\title{
Postoperative atrial fibrillation: Can an ounce of prevention eliminate a pound of cure?
}

\author{
Murray H. Kwon, MD \\ From the Division of Cardiac Surgery, Department of Surgery, David Geffen School of Medicine at UCLA, Los \\ Angeles, Calif. \\ Disclosures: Author has nothing to disclose with regard to commercial support. \\ Received for publication June 7, 2017; accepted for publication June 12, 2017; available ahead of print July 8, \\ 2017. \\ Address for reprints: Murray H. Kwon, MD, 10833 Le Conte Ave, CHS 62-229, Los Angeles, CA 90095 (E-mail: \\ mkwon@ymail.com). \\ J Thorac Cardiovasc Surg 2017;154:1652-3 \\ $0022-5223 / \$ 36.00$ \\ Copyright (c) 2017 by The American Association for Thoracic Surgery \\ http://dx.doi.org/10.1016/j.jtcvs.2017.06.028
}

Postoperative atrial fibrillation (PAOF) remains the most common complication after cardiac surgery. It has essentially become a "cost of doing business," as we concede to an approximate $40 \%$ incidence no matter what preventive measures have been used. Like 10-year allograft survival in heart transplantation or vein graft patency in coronary artery bypass grafting, these results have changed little during the past several decades. This is not for lack of considerable efforts in characterizing mechanisms, identifying risk factors, and developing various pharmacologic treatments.

Despite the fact that it is often self-limited, the potential risks of stroke, renal injury, pulmonary infections, and complications of requisite anticoagulation must not be trivialized. ${ }^{1}$ The added costs for resource use and increased lengths of stay add immense burdens to our health care system. Thus, continued efforts to overcome this barrier must be made.

Sympathetic activation and inflammation have been frequent targets of POAF prevention with varying results and have yielded no practice recommendations from Level 1 evidence. ${ }^{2}$ Strong points of the current manuscript are compelling data showing that novel manipulation of potassium channels to influence myocardial repolarization can have a favorable impact on the maintenance of sinus rhythm in an animal model of atrial fibrillation. The efficacy, despite the elimination of trypsin used in previous studies, lays important groundwork relevant to any preclinical study looking to support a future Phase 1 clinical trial. The obvious liabilities, which are noted in the manuscript, are the applicability of this animal model of induced atrial fibrillation to POAF in the human situation. The safety conclusions also hardly address the obvious concerns regarding use of viral vectors in human subjects.

The insights afforded by this animal model also highlight potential differences between atrial fibrillation occurring spontaneously and in the postoperative settings. The fact that pulmonary venous application was not necessary, for example, indicates one key difference to the "box lesion" neering efforts.

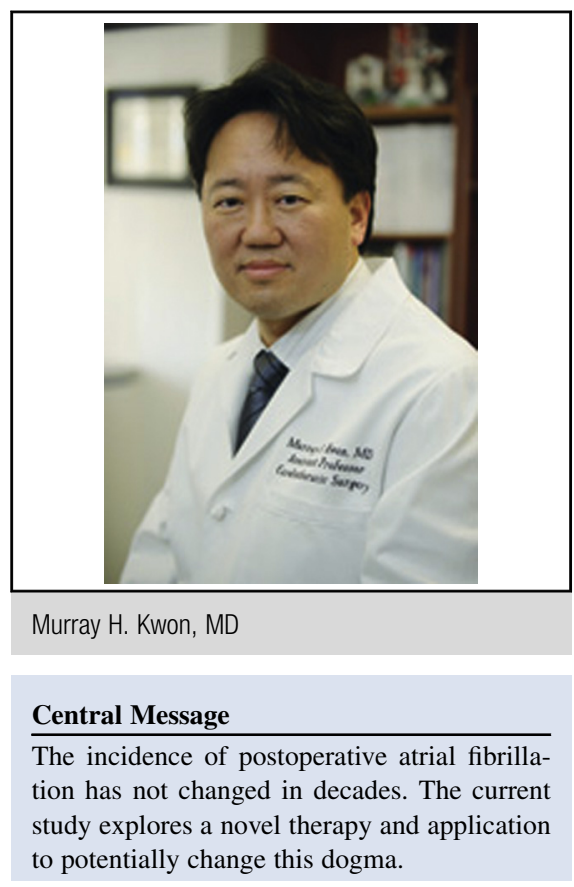

See Article page 1644.

required during the MAZE procedure for paroxysmal or persistent atrial fibrillation variants. The fact that epicardial application alone was sufficient to reduce atrial fibrillation incidence also indicates the potential importance of this layer to the reentry circuits inherent to POAF.

This study not only demonstrates the utility of targeting a relatively novel pathway inducing mutations in potassium channels to prevent POAF but also suggests a method of delivery that, up until now, has not gained significant traction, that is, the proactive, direct application of a substance to the myocardium concomitantly with cardiac surgery. The appeal of "epicardial painting" is that it is relatively straightforward, can be applied directly to the target tissues, thereby eliminating the potential for systemic toxicities, and it puts the treatment back into the hands of the operating surgeon. Although gene expression is only thought to persist for 2 to 3 weeks after application, this happens to mirror the time frame of greatest POAF risk.

Although recent landmark contributions to the literature in the area of POAF have emphasized treatment regimens, ${ }^{3}$ equal attention towards its prevention should continue and the authors should be lauded for their pio- 


\section{References}

1. LaPar DJ, Speir AM, Crosby IK, Fonner E Jr, Brown M, Rich JB, et al. Postoperative atrial fibrillation significantly increases mortality, hospital readmission, and hospital costs. Ann Thorac Surg. 2014;98:527-33; discussion 533.

2. Greenberg JW, Lancaster TS, Schuessler RB, Melby SJ. Postoperative atrial fibrillation following cardiac surgery: a persistent complication. Eur J Cardiothorac Surg. 2017;150:957-64.

3. Gillinov AM, Bagiella E, Moskowitz AJ, Raiten JM, Groh MA, Bowdish ME, et al. Rate Control versus Rhythm Control for Atrial Fibrillation after Cardiac Surgery. N Engl J Med. 2016;374:1911-21. 